\title{
Change Management Strategy for the Activities of Business Organizations
}

\author{
Irina Avdeeva ${ }^{1, *}$, Tatyana Golovina ${ }^{1}$, Andrey Polyanin ${ }^{1}$ \\ ${ }^{1}$ Central Russian Institute of Management, Branch of RANEPA, Department of Management and Public Administration, 302028 \\ Orel, Russia
}

\begin{abstract}
Within the context of modern management, business organizations need to realize that everything around them is changing: the rules of the game, the participants, the scale of activities, and the size of markets. In other words, nothing is constant. The changes may be both local and global, whereby developments may affect different fields: executive and administrative, technical and economic, social and public, informative and analytical. Managerial decisions taken inside an organization under the aforementioned conditions require sound theoretical grounds for selection in terms of potential risks and current and future economic effects. Traditionally, long-term decisions on setting goals for an activity of a business organization and determining ways to achieve them are considered within the framework of strategic planning, as a result of which a development strategy is formed. However, under current circumstances, the place and role of change management in the strategy of business organizations requires reinterpretation. The academic originality of this contribution lies in the specification of a concept for change management with regards to the activities of business organizations based on a strategic approach and adaptation to dynamically changing market conditions, including long-term planning. As part of the study, the essence of a strategic approach to change management regarding the activities of business organizations is considered, the principles of building a change management strategy are highlighted, and an algorithm for its development and implementation is proposed.
\end{abstract}

Keywords: change management, strategy, strategic management, business organizations

\section{Introduction}

Within the context of the constant search for new forms and methods of work, the relevance of improving the dynamic development of the management mechanism is increasing. At the same time, a comprehensive study of the possibilities of increasing the competitiveness of business structures on the basis of the effective management of changes in their activities is becoming a promising area of academic research.

Modern business structures function and evolve under conditions of economic uncertainty and instability, which affects many processes, which is happening both globally and within the Russian economy.

This highlights the importance of logical approaches to strategic change management in order to minimize the dangers and risks generated by negative factors and to add and benefit from the effects of positive factors.

In the case of Russia, the process trends taking place within the sphere of national entrepreneurial activities (especially in SMEs) is not very positive, which is certainly having an effect on economic relations. After considerable growth in the entrepreneurial sphere in 2018, this slowed and stabilized in 2019. When assessing the overall dynamics of the number of business organizations, this decreased by $0.3 \%$. In sectoral context, no large changes were observed, with exception to the mineral industry where the number of business organizations increased more actively. There are several reasons to explain this, including:

- global changes and the competitive recovery of the market for natural and energy resources;

- reduction of actual incomes of Russian households;

- deficit of financial assets needed for development;

- existence of considerable red-tape and executive barriers hampering the development of active business organizations and the foundation of new ones, this despite the fact that there are different federal and regional programs focused on business development and the improvement of business activity;

\footnotetext{
${ }^{*}$ Corresponding author: i-avdeeva-i@yandex.ru
} 
- $\quad$ established segment structures, whereby not only individual enterprises, but also parts of entire industrial sectors remain insufficiently receptive to innovation implementation.

The goal of the research is to formulate a model of reasoning that describes the management of changes in the activities of business organizations from a strategic point of view.

\section{Methodology}

Within the framework of the research, a strategic review of research articles on change management was conducted. Based on the results obtained, the key principles of change management strategy for the activities of business organizations was determined, and recommendations for the implementation of a mechanism for developing a change management strategy for increasing stability and competitiveness given.

The basis of the theoretical and methodological study was academic papers by both national and international scholars. The papers touch upon management decisions regarding the development of business organizations and the enhancement of efficiency.

In general, development strategy implies how an organization implements and adheres to it in order to fulfil its main long-term goals. The authors agree with the conclusions of P.A. Argenti, who focuses on the development difficulties companies face from competitors when they only take tactical decisions aimed at achieving short-term goals, without having any strategy in place [1].

At the same time, one cannot but agree with the conclusions of Charles Lindblum, who demonstrates, on the basis of the incremental model of decision-making, that in highly uncertain, turbulent conditions, the decision-making process should be carried out through an indefinite and disordered series of small movements from "pain points" of the day, and not on the basis of predetermined goals that usually remain unattainable. Moreover, in situations of uncertainty, G. Simon shows, through his descriptive model, which takes into account personal experience and the insight of management personnel, intuitive decision-making wins.

At present, strategic management, which has quite a wide theoretical base, is a study subject for many scholars.

American authors A. Thompson and A.J. Strickland give the following model: company strategy - a combination of business organization methods aimed at achieving company goals and customer interests. Scholars point out the fact that working out a development strategy is the main task of management, thereby taking into consideration that effective management is not only based on the choice of a successful strategy and its correct implementation, but also on the unexplored impact of transformation processes at certain economic lifecycle stages as a result of the influence of the external environment [2]

According to H. Mintzberg, a strategy is a consistent, agreed and integrated structure for management decisions [3]. At the same time, scholars assign a leading role to the potential of personnel in business organizations. They believe that middle and lower-level leaders play a huge role in the implementation of changes. Teams, projects, departments and divisions managers have a unique and influential role to play. It is these leaders who must communicate the vision for change.

In literature, different approaches exist for determining the content of the stages of strategic management.

The most widespread are the models of F. David, A. Thompson and R. Lynch. David's model assumes the sequential implementation of 3 stages: strategy development, strategy implementation and strategy evaluation [2, 4]. At the same time, no attention is paid to the most important component of the strategic approach, namely the control and monitoring stage.

The problem of change management is reflected in numerous domestic and foreign works. For this study, the authors relied on the works of R. Kh. Hall, M. Hammer, D. Harrington, W. Bridges, K. Levin, T. Cummings, K. Worley, E. Cameron, P. Cotter, Rosabeth Moss Kanter, and many others. The emphasis in these studies is that many organizations have mastered the operational or structural side of change, but that they pay little attention to the human dimension of change. To obtain the desired results from a new system, initiative or a new direction, organizations need to master not only the organizational and management aspects of change, but also to understand the issues of leadership in change.

From this point of view, the research conducted by Rosabeth Moss Kanter deserves to be highlighted. She reasonably argues that no matter what strategy top managers develop, it cannot be implemented in practice if managers do not encourage subordinates to search for management decisions.

The problem within this study field is that most researchers ignore the process of change management when they consider the management mechanisms that can radically transform the activities of business organizations.

The methodological basis for the research was the theory of strategic management and the dynamic abilities of business organizations. The main methods of work are structural and logical, bibliographic and criteria analysis. 
The presented concept is focused on the need to include a change management strategy in corporate strategic management. At the same time, it is necessary not only to take into account the methodology of strategic management, but also to formulate specific principles and methodological approaches that take into account the nature of changes and the magnitude of their influence on the dynamic development of business organizations. Until now, domestic and foreign scholars have not formulated the basic postulates of change management integration into the development strategy of economic systems of various levels. Currently available scientifically based methodological approaches are fragmented and focused on individual stages of the lifecycle of business organizations or specific strategic management decisions.

\section{Results and Discussion}

Strategic management has become an integral part of business structures and its absence not only complicates their function, but even makes it impossible.

In determining its development strategy, the administration of a business organization should clearly know the direction of travel, i.e. what should be continued and what should be implemented [5]. The answers to these questions help a company determine their strategy. The choice of business development strategy, as a development stage, is an integral part of strategic management, which enables a company to move towards its goal in the best possible way. It is the right choice of strategy that helps manifest the skills of company management, its competence and professionalism [6]. Returning to the stages of working out a strategy, and with consideration for the essence of strategic management, one can see that this activity is based on the collection, processing, analysis and exchange of information both with the internal and external environments.

Big companies are not able to react quickly to the changes in the Russian economy. Small businesses are the impetus for the general state of affairs in the Russian economy. They are the most sensitive to an increase or decrease in the level of profits within various economic sectors.

Within the context of ineffective reprocessing, large companies export fixed capital. Small companies, unlike large ones, do not have such opportunities. This contributes to the need for them to quickly revise their production and marketing activities. At the same time, improving the efficiency of their activities and their ability to overcome crisis situations is important for the country's economic recovery.

Under current market conditions, it is therefore vitally important to competently manage transformations in business organizations and increase the efficiency of their activities. It is therefore clear that there is a need to specify methodological approaches to planning a strategy for the change management of activities of business organizations [7].

The key conflicts that business organizations face on the path towards change management, as well as their characteristics, are presented in Table 1.

Table 1. Key contradictions brought about by organizational change

\begin{tabular}{|l|l|}
\hline \multicolumn{1}{|c|}{ Conflict } & \multicolumn{1}{c|}{ Content } \\
\hline $\begin{array}{l}\text { Between desired and } \\
\text { needed }\end{array}$ & $\begin{array}{l}\text { This is characterized by the motivational struggle between what needs to be done at the moment and } \\
\text { what one wants to do. In most cases, the process of change dictates the need for specific actions, which } \\
\text { often require making strong-willed executive decisions. However, there are often cases of voluntary } \\
\text { reorganizations. }\end{array}$ \\
\hline $\begin{array}{l}\text { Between traditional and } \\
\text { new }\end{array}$ & $\begin{array}{l}\text { This is the conflict between traditional, often practiced and automatic actions and innovations, which } \\
\text { require additional efforts to muster and implement them. }\end{array}$ \\
\hline $\begin{array}{l}\text { Between current and } \\
\text { future benefits }\end{array}$ & $\begin{array}{l}\text { This is explained by the fact that operational activities and processes that proceed according to an } \\
\text { established scheme deliver benefits in the current period and ensure business' operations, whereas the } \\
\text { introduction of changes promises to bring benefits in the future, but without guaranteeing them. }\end{array}$ \\
\hline $\begin{array}{l}\text { Between the top } \\
\text { management and the staff }\end{array}$ & $\begin{array}{l}\text { This is characterized by a three-level system of resistance factors: unwillingness to overcome } \\
\text { difficulties, take on additional obligations; high group cohesion in a situation where the goals of the } \\
\text { group and the organization do not coincide; lack of a clear strategy for the development of the } \\
\text { organization; imperfect system of organizational communications. }\end{array}$ \\
\hline
\end{tabular}

Source: Authors.

Due to the fact that the transformation process of business organizations under current operating conditions is of a constant nature, organizations therefore face difficulties and controversies because of change [8]. Although certain management decisions are viewed as an adequate response to such challenges in the micro- and macro-environment, they in turn generate even greater changes [9].

Successful change management inside business structures means the adoption and implementation of managerial decisions, which is a sufficient condition for a desired outcome and the achievement of goals with respect to resources of the company.

The analysis of the approaches to the development of change management strategy allowed us to come to the conclusion that it is necessary to establish scenario- and project-based approaches and to ensure conformity with the company-wide business development strategy [11]. 
The scientific explanation of the methodological developments under such conditions is predetermined by the theoretical basis, which, as a rule, is a set of principles that must be taken into account (see Figure 1).

In order to properly understand the strategic plan of a company in terms of initiating and implementing measures for the adaptation of business structures in a dynamic and unpredictable environment, it is necessary to talk about change management strategy within the context of having a functional strategy, one that is subordinate to the general corporate strategic goals and principles [12], while having its own set agenda for a determined time period [13]. The aforementioned strategy should therefore conform with (or be developed within the set boundaries of) the general corporate strategy [14] in order to:

1) promote or ensure the achievement of the goals adopted under the general corporate strategy;

2) establish the basis for further development of competitiveness inside business organizations;

3) maintain and strengthen current positions of business organizations (market, technological, financial, etc.).

At the same time, the process of keeping and strengthening the current position of the company should not be considered separately from strategic planning because current or expected issues must be dealt with using the appropriate tools for the development, composition and implementation of both the general corporate and functional strategies (see Figure 2).

The role of a change management strategy is subject to the strategic goals of business organizations and therefore changes accordingly $[15,16,17]$, it may range from a complete profile change to the maintenance of current activities and sustainability.

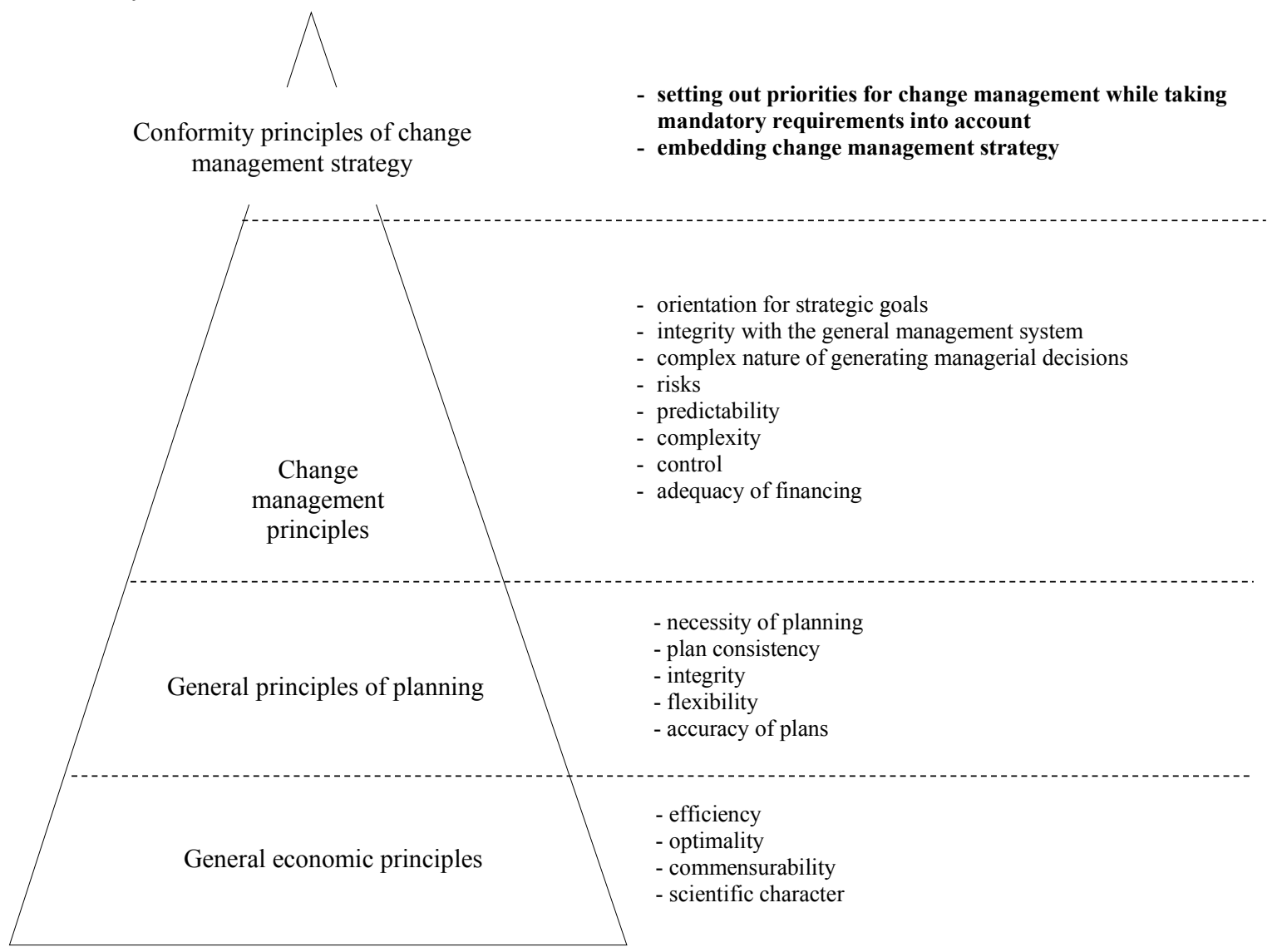

Figure 1. Recommended principles for the development and implementation of a change management strategy in business organizations

Source: compiled by the authors.

\section{Conclusion}

The uncertainty and instability of the external environment has a significant impact on the quality of the management activities of business organizations. This is what is driving the increased interest in this field, both in terms of theory and entrepreneurial activities in practice.

The above referenced framework actively employs the advantages of a strategic approach to change management because it: 
- $\quad$ presents an opportunity to combine and sustain subsystems relative to various levels of complexity;

- conveniently demonstrates existing advantages and disadvantages;

- ensures self-management and implementation of information and communication technologies with the perspective to minimize human participation in the analysis and elaboration of the best possible solution based on the elements of artificial intelligence.

The theoretical significance of the study lies in the improvement of business management based on the use of a strategic approach, one that is appropriate for a period of economic instability. The proposed change management tools make it possible to effectively solve management problems in order to fulfil the economic interests of business organizations.

The practical importance of the study is driven by the use of the original algorithm for change management strategy development, which enables improvements in the sustainability and competitiveness of business organizations.

Future research will be linked to increasing the efficiency of change management through the active use of information systems, including artificial intelligence and neural networks.

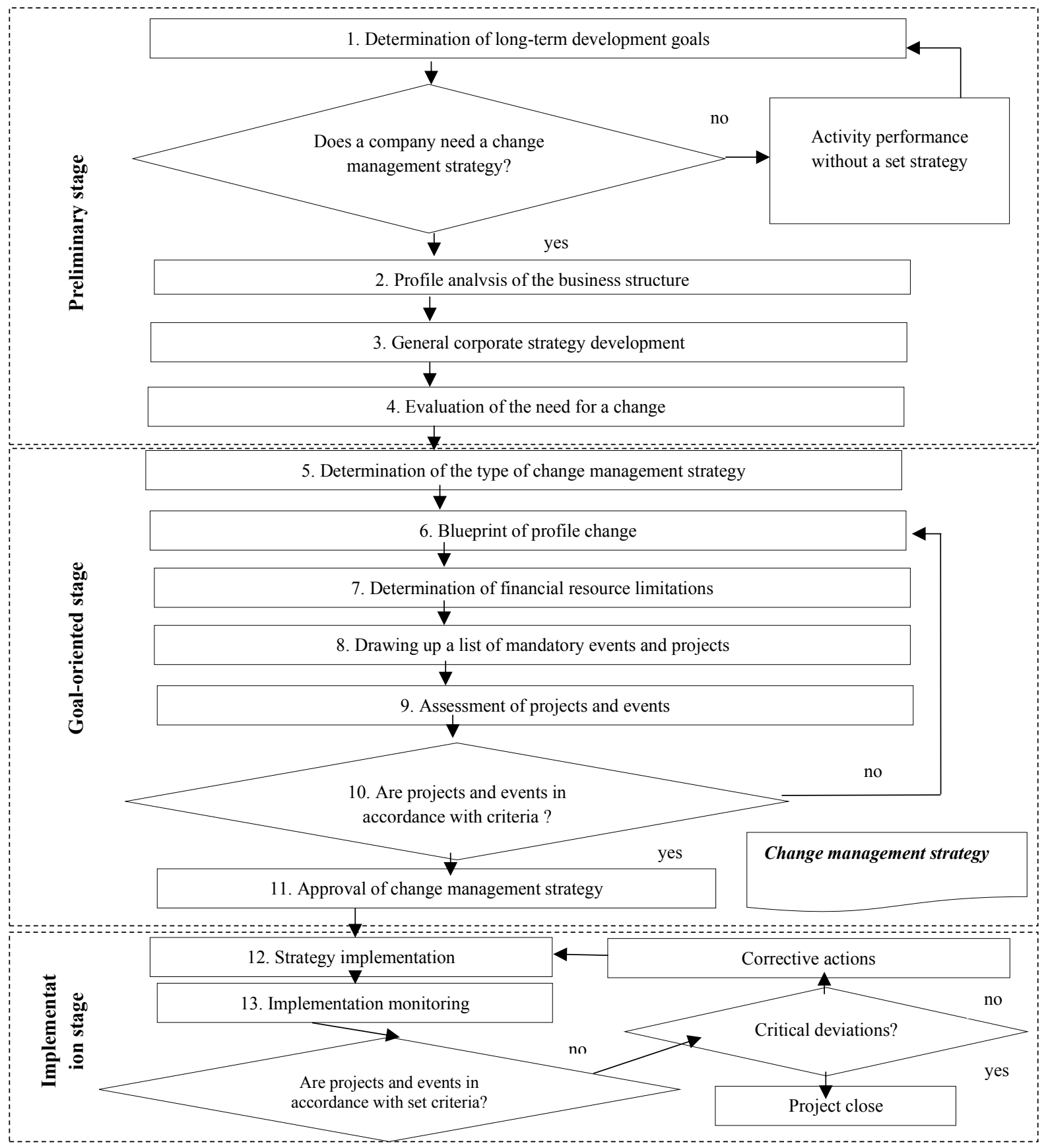

Figure 2. Algorithm for change management strategy development and implementation in business organizations

Source: compiled by the authors. 


\section{References}

1. P. A. Argenti, R. A. Howell, K. A. Beck, The strategic communication imperative. MIT Sloan Management Review. 46(3), 82-90 (2005)

2. A. Thompson, A. J. Strickland, Crafting and Implementing Strategy: Text and Readings. New York: Irwin Professional Publishing (1997)

3. H. Mintzberg, J. A. Waters, Of strategies, deliberate and emergent. Strategic Management Journal. 6(3), 257$272(1985)$

4. A. Awang, A. Kassim, A. M. Noor, N. Shukor, A. Z. Shaari, S. Amran, S. A. Khalid, Strategic Entrepreneurship Model for Economic Transformation: Malaysian Evidence. Asian Social Science. 11(7), 19-34 (2015)

5. M. A. Hitt, R. D. Ireland, R. E. Hoskisson, Strategic management: Competitiveness and globalization. Stamford: Cengage Southwestern Publishing Co. (2004)

6. S. Elbanna, B. A. Katheeri, M. Colak, The harder firms practice strategic management, the better they are. Strategic Change. 29(5), 561-569 (2020)

7. F. Hofmann, M. Jaeger-Erben, Organizational transition management of circular business model innovations. Business Strategy and the Environment. 29(6), 2770-2788 (2020)

8. H. Linkweiler, Change management and post-acquisition considerations for smoothly implementing new management strategies. Journal of Airport Management. 13(1), 31-38 (2019)

9. D. Binci, S. Belisari, A. Appolloni, BPM and change management: An ambidextrous perspective. Business Process Management Journal. 26(1), 1-23 (2019)

10. F. Deutscher, F. B. Zapkau, C. Schwens, M. Baum, R. Kabst, Strategic orientations and performance: A configurational perspective. Journal of Business Research. 69(2), 849-861 (2016)

11. V. M. Repnikova, O. N. Bykova, P. V. Stroev, D. E. Morkovkin, S. N. Kurbakova, Improvement of approaches to the strategic development management of enterprise. Entrepreneurship and Sustainability Issues. 8(1), 301$312(2020)$

12. I. Vandangeon-Derumez, A. Djedidi, E. Szendy, An experiential approach to learning about change management. Journal of Management Development. 38(9), 708-718 (2019)

13. N. Yunita, N. Nasir, M. Adam, N. Darsono, A structural relationship of change management and its supply change strategy for improving officer and organizational performance. International Journal of Supply Chain Management. 9(4), 1210-1221 (2020)

14. M. C. Díaz-Fernández, M. R. González-Rodríguez, B. Simonetti, The Moderating Role of Top Management Team Diversity in Strategic Change in a Multicultural Context. European Management Review. 6(4), 957-973 (2019)

15. R.-G. C. Dirksen, The strategy of communication in organizational development 2.0. Gruppe. Interaktion. Organisation. Zeitschrift fur Angewandte Organisationspsychologie. 51(3), 345-352 (2020)

16. G. Cattani, J. F. Porac, H. Thomas, Categories and competition. Strategic Management Journal. 38(1), 64-92 (2017)

17. M. Y. Veselovsky, M. A. Izmailova, E. N. Lobacheva, P. P. Pilipenko, G. A. Rybina, Strategic management of innovation development: Insights into a role of economic policy. Entrepreneurship and Sustainability Issues. 7(2), 1296-1307 (2019) 